\title{
Fractal analysis of tropical karst relief - South China Karst case study
}

\author{
Viacheslav ANDREYCHOUK ${ }^{1, *}$, Tomasz BLACHOWICZ² and Maciej DŁUŻEWSKI ${ }^{1}$ \\ 1 University of Warsaw, Faculty of Geography and Regional Studies, Krakowskie Przedmieście 30, 00-927 Warszawa, Poland \\ 2 Silesian University of Technology, Institute of Physics - Center for Science and Education, Konarskiego 22B, 44-100 \\ Gliwice, Poland
}

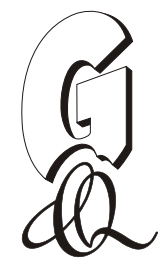

Andreychouk, V., Blachowicz, T., Dłużewski, M., 2019. Fractal analysis of tropical karst relief - South China Karst case study. Geological Quarterly, 63 (4): 729-740, doi: 10.7306/gq.1493

\begin{abstract}
Areas of tropical karst create the most spectacular earth landscapes from a geomorphological perspective. These areas are characterized by a variety of specific forms resulting from the long-term karst-erosion dismemberment of terrains in favourable humid tropical conditions. Tropical karst areas are extremely diverse from a geomorphological point of view both in terms of local conditions of development and developmental stages. Among the many types of karst relief, the following two basic types can be recognized: fenglin (tower karst) and fengcong (cone karst). The other types can be treated as a mixture of these two basic types. To find potential quantitative rates characterizing the two main types, as well as the mixed types, we calculated fractal dimensions and cover factors of 17 areas located within the two well-known regions of South China Karst Guilin and Huanjiang. The calculations show that the numerical characteristics obtained, especially the cover factor parameter, can be useful as complementary tools in the recognition and typology of tropical karst relief and landscapes.
\end{abstract}

Key words: fractal dimension, cover factor, tropical karst, South China Karst.

\section{INTRODUCTION}

This paper focuses on the morphometric analysis of basic types of tropical karst relief using examples of their Chinese varieties, which can be classified as cone and tower karst, noting certain differences and specific features. In this study we explore relatively simple morphometric indicator(s) that can be helpful for quantitative estimation of both types of karst relief, as well as of transitional varieties. Two parameters are proposed for analysis: the fractal dimension and the cover factor.

There are two main goals of our analyses. The first goal is to check whether karstic relief such as fengcong and fenglin have fractal properties, and if so - can fractal parameters be helpful for the purposes of its typology? The second aim is to verify whether there is a correspondence between such indicators as fractal dimension and cover factor in order to check their informative potential and confirm the sense of their common usage.

\section{FENGLIN AND FENGCONG KARST}

\section{FENGLIN AND FENGCONG KARST IN CONTRAST} TO CONE AND TOWER KARST

It is well known that the karst relief of humid tropical regions is highly specific (Lehmann, 1936; Wissmann, 1954; Sweeteng,

\footnotetext{
* Corresponding author, e-mail: w.andrejczuk2@uw.edu.pl
}

Received: March 7, 2019; accepted: September 8, 2019; first published online: November 18, 2019
1958, 1972; Balazs, 1973; Williams, 1978, 1987; Jennings 1985; Pham, 1985; Ford and Williams, 1989; Pfeffer, 1993; Song et al., 1993; Monroe, 1996; Salomon, 2000; Salomon and Pulina, 2005). This karst is characterized, in contrast to the karst of other climatic regions, by the occurrence of convex, positive landforms, creating specific morphological complexes and landscapes with a characteristic course of morphogenetic processes. The predominance of convex, conical and tower-like forms is an integrated result of the interaction of many factors and circumstances (geological, structural, hydrological, etc.), but it primarily results from a relatively high activity of karstification in warm and wet subtropical and tropical conditions, as well as from the long-lasting (millions and tens of millions of years) history of karst evolution in the context of slow tectonic uplift (see e.g., Brook and Ford, 1978; Zhang, 1980; Sweeting, 1986; Wang, 1986; Williams, 1987; Xiong, 1992; Silar, 1996; Liu, 1997; Yuan, 2004; Waltham, 2008). A tropical (subtropical in the case of China) karst terrain usually contains different types and evolutionary stages of mature karst landscapes with morphological features starting from fragmented hilly uplands to cone-like and tower-like dissected terrains and finally ending with flat alluvial areas, individual karst towers and residual hills (Zhang, 1980; Zhu, 1982, 2005; Chen, 1988; Ford and Williams, 1989; Sweeting, 1989; Salomon, 2000; Yuan, 1991, 2004; Gunn, 2004; Waltham, 2008, 2011).

Despite the presence of a common morphological denominator - the visual predominance of positive karst forms - tropical karst terrains are extremely diverse from the landscape-morphological perspective since geological and climate prerequisites in different areas are usually strongly influenced by local conditions (lithological, structural, geotectonic, hypsometric, geomorphologic, hydrogeological, etc.). Never- 

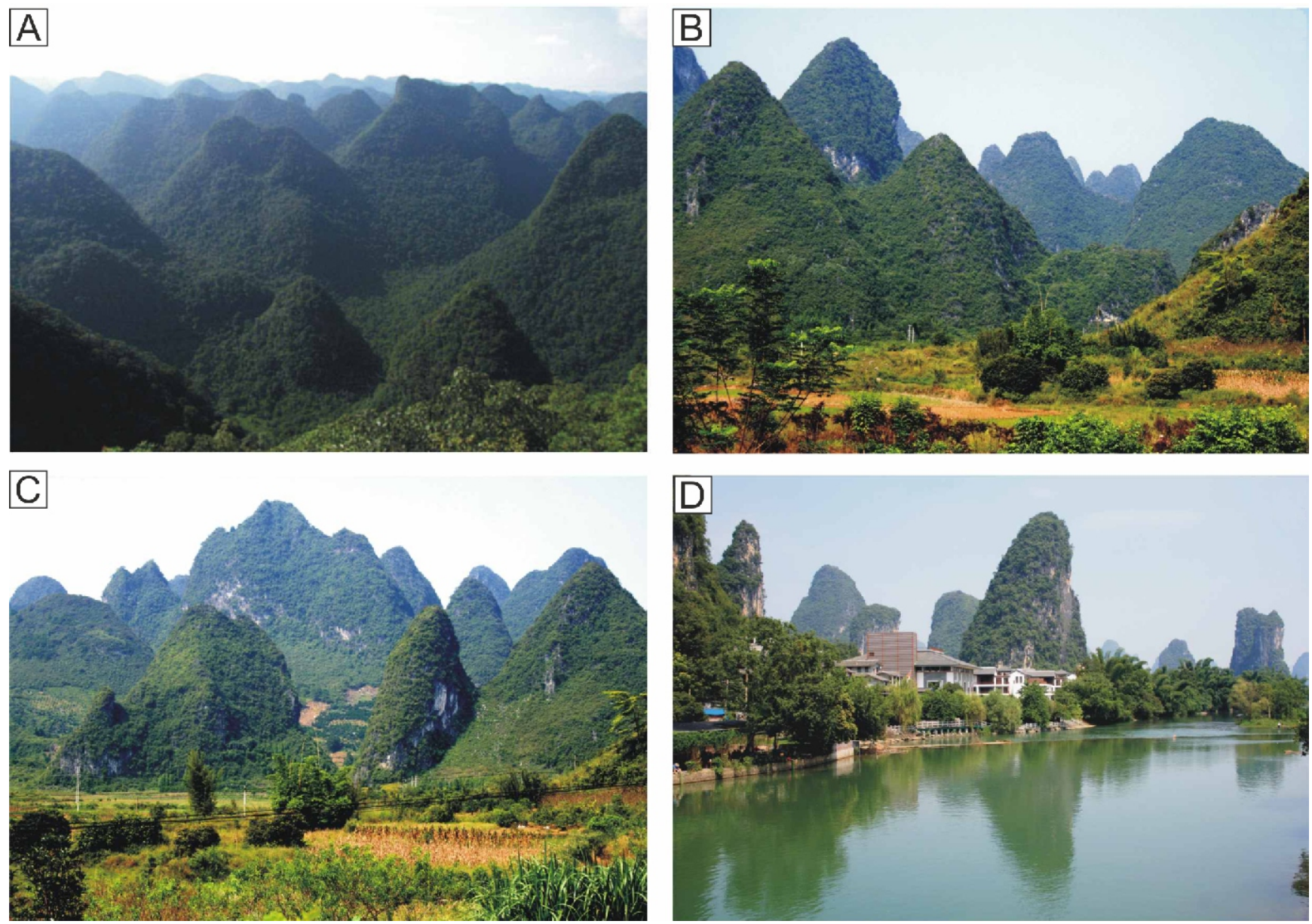

Fig. 1. Typical examples of the fengcong (cone) karst (A) and the fenglin (tower) karst (D), as well as their mixed (transitional) types: the transitional fengcong (B) and transitional fenglin (C)

Descriptions and sources: A - source: internet, karst in the region of Huanjiang, B-D - photos by V. Andreychouk, karst from the area of Jangshuo, South China

theless, most of the mature karst landscapes are more or less similar to two basic types: cone karst and tower karst (Sweeting, 1995; Salomon, 2000; Liu et al., 2001; Li Yu, 2002; Salomon and Pulina, 2005; Zhu, 2005; Waltham, 2008; Andreychouk and Dłużewski, 2015). These terms appeared in the first half of the 1920s and were introduced into the scientific literature by Lehmann (1926 - Kegelkarst; this is the German equivalent of cone karst), Danes (1911) and Sweeting (1958 cockpit karst), and Wissmann (1954 - Turmkarst; this is the German equivalent of tower karst). In general, cone karst terrains are usually represented by numerous conical (dome-shaped, hemispherical, etc.) forms with closed depressions between them. Classic examples of cone karst areas are known from Central America (Jamaica, Puerto Rico, Cuba-Oriente) and South-East Asia (Philippines - Bohol area and Java-Gunung Sewu area). Tower karst is known from South China, Laos and Cuba (Sierra de los Organos area).

Research carried out in the last several decades in South China have fundamentally enriched the list of classic tropical karst regions and the knowledge of these regions. Importantly, it turned out that this region is unique, on the world scale, with respect to the diversity of tropical karst morphology. Similar to other regions of the world where tropical karst occurs, Chinese researchers also distinguish two basic types, fengcong and fenglin, which are identified by most researchers as cone karst and tower karst, respectively. It should be noted, however, that such identification is misleading. While fenglin is equivalent to tower karst and classically represents it, in the case of fengcong (allegedly cone karst), the adequacy of the terminology is much less explicit. These issues were subject to a detailed analysis by Waltham (2008) devoted to the terminological analysis of these concepts. It would be more reasonable to say that both fenglin and especially fengcong represent classic but specific (regional, Chinese) types (subtypes) of cone and tower karsts.

There are several regional differences between these types of karst globally, especially from the morphological and the morphometric points of view. There is also a difference in the perception of landscapes of both types in the West and in China. Western scholars trying to find the proper morphological and morphometric indicators for typological analysis of cone and tower karst focus on the convex elements of the sculpture, while for Chinese scientists - due to historic and very practical reasons - the presence of flattened depressions and flat areas separating the convex forms is more important (Waltham, 2008). 
EVOLUTIONARY CONCEPTS OF FENGCONG AND FENGLIN KARST DEVELOPMENT

In this study, we understand and treat fengcong and fenglin karst as specific types of tropical (subtropical) karst terrain, and these comprehensive geomorphological formations possess their own sets of characteristic features. Fengcong karst is the morphological type in which limestone basement of significant thickness is dissected to a given (often different) depth (several tens or several hundred of metres) creating a more or less regular pattern consisting of relatively isolated cones and clusters of cones, as well as depressions and small valleys placed between them. Usually, in terms of surface morphology, positive forms (cones) dominate over negative depressions in such types of landscape (Fig. 1A). Depressions and valleys between cone hills of different but similar heights are usually flattened and filled with clastic and residual materials. Fengcong karst develops in conditions with a relatively deep karst water level. Therefore, it is characterized by active ground water circulation (vadose). Characteristic of this type of karst is the occurrence of ponors in the bottoms of blind valleys, capturing surface waters and taking them underground. This is the main mechanism of channel-type cave formation in this type of karst. Fengcong karst can be treated, in general, as an active karst.

Fenglin karst is characterized by widespread, numerous residual hills (towers) and cones dotting a flat karst plain and occurring both as single forms and small clusters (Fig. 1). In fenglin karst, flat areas dominate over towers and cones. This type of karst relief is less regular and much more chaotic (spatially disorganized) than cone karst. In fenglin karst, former depressions between cones are joined via enlargement and coalescence into more or less continuous flat areas formed at the groundwater level (karst plain). In such types of karst landscapes, surface water circulation is dominant. Rivers and their tributaries meandering between residual hills are supplied mainly by rainwater. Flat areas are usually covered with a mix of autochthonic residual clay products resulting from limestone karstification and allochthonous alluvial sediments. Fenglin karst may be treated as non-active karst based on modelling processes.

Concerning genetic relations between these two types of tropical karst, two main approaches (hypotheses) exist (Williams, 1987; Ford and Williams, 2007; Zhu, 2005; Waltham, 2008).

The first approach assumes that fengcong and fenglin karst represent evolutionary stages of karst landscape development sequentially from a previously hilly and cone karst-dominated terrain, which is more "compact" and regular with predominantly positive forms, gradually through transitional stages - in accordance with progressive deepening of the denudation base - to fenglin karst, which is weakly ordered with predominantly negative forms, to alluvial plains with residual hills, representing the very mature final stages of karst planation. The fengcong karst represents, in this case, an earlier stage when the bottoms of depressions can be found although significantly above the groundwater level. This type of karst develops mostly vertically. Fenglin karst reflects a much more advanced stage of landscape development, especially when the negative forms reach the groundwater level and merge, creating a common plain area. This type of karst develops mostly laterally. Stable and slow tectonic uplift supports such evolutionary trends. Between typical fengcong and fenglin karsts, transitional, mixed types (i.e., evolutionary stages) occur. Most of the general schemes of evolution of tropical karst areas, prepared by researchers outside China, refer to this approach (e.g., Balazs, 1973; Gvozdetskiy, 1988; Waltham, 2008).
The second approach allows relatively independent development of both types of geomorphological landscape, depending on the local geotectonic, structural-geological, hypsometric and hydrogeological conditions. In this case, cone and tower karst, as well as their mixed types, regardless of their adjacent location, reflect the differentiation of local developmental conditions. These two alternatives were examined by Williams (1987, 1988) and Zhu (1988), who concluded that both scenarios can exist (Ford and Williams, 2007). Investigations show that these two tendencies may also overlap with each other in space and time. Since there are many studies on this subject, neither methodology can be considered well established (Zhu, 1988 1991a, b, c; Zhu et al., 1988; Yang, 1993; Xiong, 1994; Yu, 2003). Nevertheless, the first approach seems to be accepted today by an increasing number of researchers.

The problem investigated belongs partially within research into fractal properties of karst (Curl, 1986; Laverty, 1987; Chilès, 1988; Feder, 1988; Havlin and Ben-Avraham, 2002; Maramathas and Boudouvis, 2006; Pardo-Igúzquiza et al., 2014, Kambesis et al., 2015) and partly refers to the authors' previous works (Andreychouk et al., 2013; Blachowicz and Andreychouk, 2016).

\section{RESEARCH AREA - SOUTH CHINA KARST}

In China, karst rocks can be found over a surface covering approximately $1,250,000 \mathrm{~km}^{2}$, which is $13 \%$ of the total area of China (Yuan et al., 1991). The South China Karst, the most compact of all karst regions, covers an area of over 0.5 million $\mathrm{km}^{2}$ (40\% of all Chinese karst regions; South China Karst nomination, 2013). It spans $1380 \mathrm{~km}$ from west to east and $1010 \mathrm{~km}$ from north to south. The geographical coordinates of the maximum karst region range are as follows: $98^{\circ} 36^{\prime}-116^{\circ} 05^{\prime} \mathrm{E}$, $22^{\circ} 01^{\prime}-33^{\circ} 16^{\prime} \mathrm{N}$. The total area with this range of coordinates equals $1,054,000 \mathrm{~km}^{2}$, while the pure karst region is $550,000 \mathrm{~km}^{2}$ (South China Karst nomination, 2013).

To the north, the region extends to the southern hills of the mountain range of Cinlin (Tsinling); to the south, into the Guangxi Basin (a geological-geomorphological unit of South China); in the west, up to the Hengduan Mountains; and in the east, up to the Luoxiao Mountains. Administratively, the region belongs to the Yunnan, Guizhou and Guangxi provinces and partially to the Chongging, Sichuan, Hunan, Hubei, and Guangdong provinces. Hypsometrically, the whole region gradually decreases in elevation from west to east, from $2100 \mathrm{~m}$ to $110 \mathrm{~m}$ a.s.l. The central part of the region is occupied by the Yunnan-Guizhou Plateau (South China Karst nomination, 2013).

The South China Karst is the world's largest karst area of tropical karst. No other tropical karst nor any other type of karst creates such a large and consistent karst area. There is no other place in the world where karst in general, including tropical karst, possesses such meaningful and impressive landscape-geomorphological properties (Williams, 1987; Zhu 1992; Sweeting, 1995; Waltham, 2008, 2011). This is why these impressive karst landscapes were inspirational to artists for millennia, especially to painters: long ago, they became an inherent component of the national culture and symbolism, present not only in art works but also in other areas of life, for example, depicted on banknotes.

For the quantitative analysis, two regions in the South China Karst were chosen: a well-known region close to the city of Guilin, and the region of Huanjiang. Both regions, due to the unique characteristics of their geomorphological landscapes, were indexed in the World Heritage List of UNESCO (Fig. 2). 


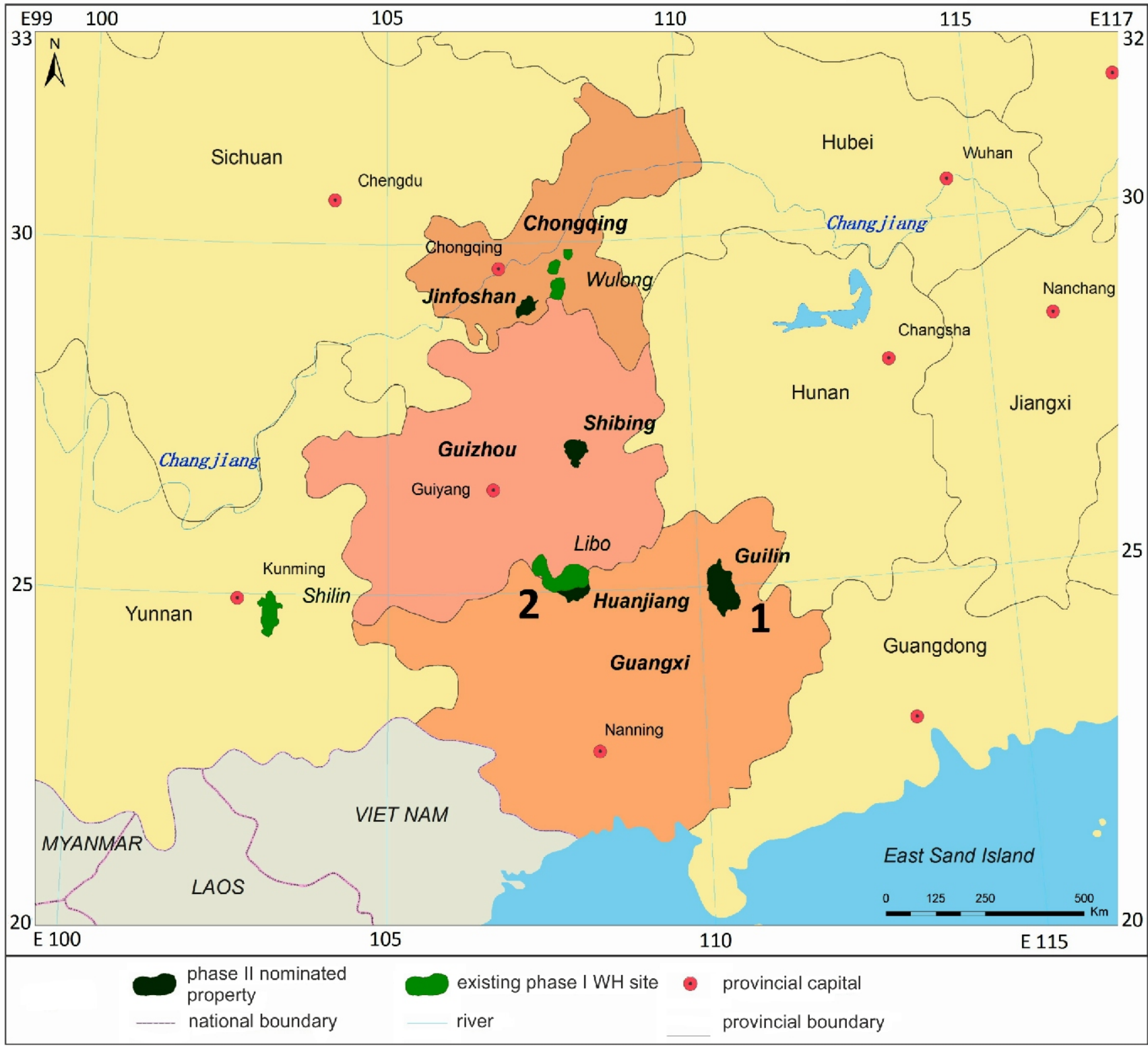

Fig. 2. Geographical location of the South China Karst regions inscribed into the World's Heritage List of UNESCO on a background of the administrative division of South China

Analysed regions are marked as 1 (Guilin) and 2 (Huanjiang; South China Karst nomination, 2013, modified)

The Guilin karst (Guangxi Province) is the most imposing region, on a world scale, of cone karst, especially due to its tower karst (Fig. 3). As noted above, tower (fenglin) karst, which developed at the groundwater level (near the local base of denudation), is modelled by surface watercourses (in the past being beneath the ground) meandering between karst towers and undercutting their bases. The Guilin karst region is famous for its charming landscapes of that type. In addition, cone karst is widely represented there, but importantly, the transitional (between fengcong and fenglin) subtypes can also be found there.

The Huanjiang karst (also Guangxi Province) represents a classic area of the fengcong type with its transitional steps evolving into fenglin karst (Fig. 4). This area consists of a com- bination of limestone karst mounds of various (from several tens up to several hundred metres) heights and dolines and depressions between them, with ponors and caves guiding meteoric and surface waters into the underground.

\section{METHODOLOGY OF RESEARCH}

The investigations consisted of two main steps. First, the modelled sub-regions were chosen from the topographical maps of the Guilin and Huanjiang regions, representing classic fenglin (Guilin and Huanjiang) and fengcong (Huanjiang) types based on the morphogenetic criteria described above. The 


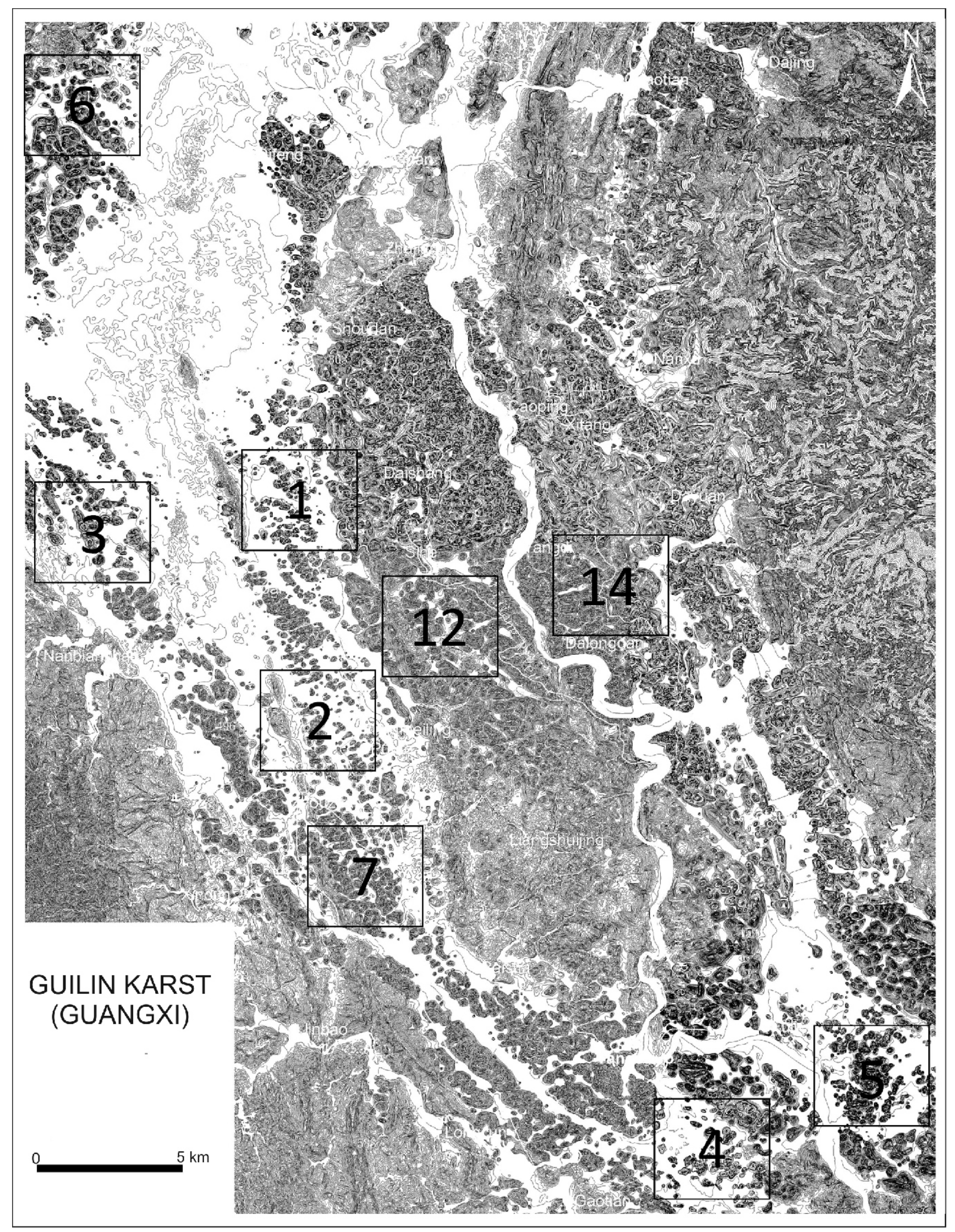

Fig. 3. The outline of the Guilin region topographical map with the sub-regions (see Table 1) chosen for the fractal analysis (on the base of South China Karst nomination, 2013, modified) 
Table 1

Calculated capacity fractal dimensions, correlation fractal dimensions, and cover factors of the investigated areas

\begin{tabular}{|l|c|c|c|c|}
\hline $\begin{array}{c}\text { Area } \\
\text { (number on the } \\
\text { map and index) }\end{array}$ & $\begin{array}{c}\text { Capacity fractal } \\
\text { dimension }\end{array}$ & $\begin{array}{c}\text { Correlation fractal } \\
\text { dimension }\end{array}$ & $\begin{array}{c}\text { Cover factor } \\
\text { (black pixels/ } \\
\text { all pixels) }\end{array}$ & $\begin{array}{c}\text { Karst types } \\
\text { and subtypes }\end{array}$ \\
\hline $1-\mathrm{FL}_{1}$ & 1.640 & 1.515 & 0.321 & fenglin \\
\hline $2-\mathrm{FL}_{2}$ & 1.606 & 1.435 & 0.324 & fenglin \\
\hline $3-\mathrm{FL}_{3}$ & 1.550 & 1.497 & 0.338 & fenglin \\
\hline $4-\mathrm{FL}_{4}$ & 1.554 & 1.465 & 0.370 & fenglin \\
\hline $5-\mathrm{FL}_{\mathrm{t} 1}$ & 1.684 & 1.558 & 0.528 & mixed \\
\hline $6-\mathrm{FL}_{\mathrm{t} 2}$ & 1.724 & 1.683 & 0.604 & mixed \\
\hline $7-\mathrm{FL}_{\mathrm{t} 3}$ & 1.743 & 1.742 & 0.614 & mixed \\
\hline $8-\mathrm{FC}_{\mathrm{t} 1}$ & 1.811 & 1.761 & 0.674 & mixed \\
\hline $9-\mathrm{FC}_{\mathrm{t} 2}$ & 1.821 & 1.770 & 0.693 & mixed \\
\hline $10-\mathrm{FC}_{\mathrm{t} 3}$ & 1.823 & 1.782 & 0.732 & mixed \\
\hline $11-\mathrm{FC}_{\mathrm{t} 4}$ & 1.837 & 1.789 & 0.760 & mixed \\
\hline $12-\mathrm{FC}_{\mathrm{t} 5}$ & 1.677 & 1.743 & 0.777 & mixed \\
\hline $13-\mathrm{FC}_{1}$ & 1.829 & 1.794 & 0.800 & fengcong \\
\hline $14-\mathrm{FC}_{2}$ & 1.689 & 1.774 & 0.807 & fengcong \\
\hline $15-\mathrm{FC}_{3}$ & 1.834 & 1.800 & 0.822 & fengcong \\
\hline $16-\mathrm{FC}_{4}$ & 1.844 & 1.805 & 0.850 & fengcong \\
\hline $17-\mathrm{FC}_{5}$ & 1.853 & 1.823 & 0.856 & fengcong \\
\hline
\end{tabular}

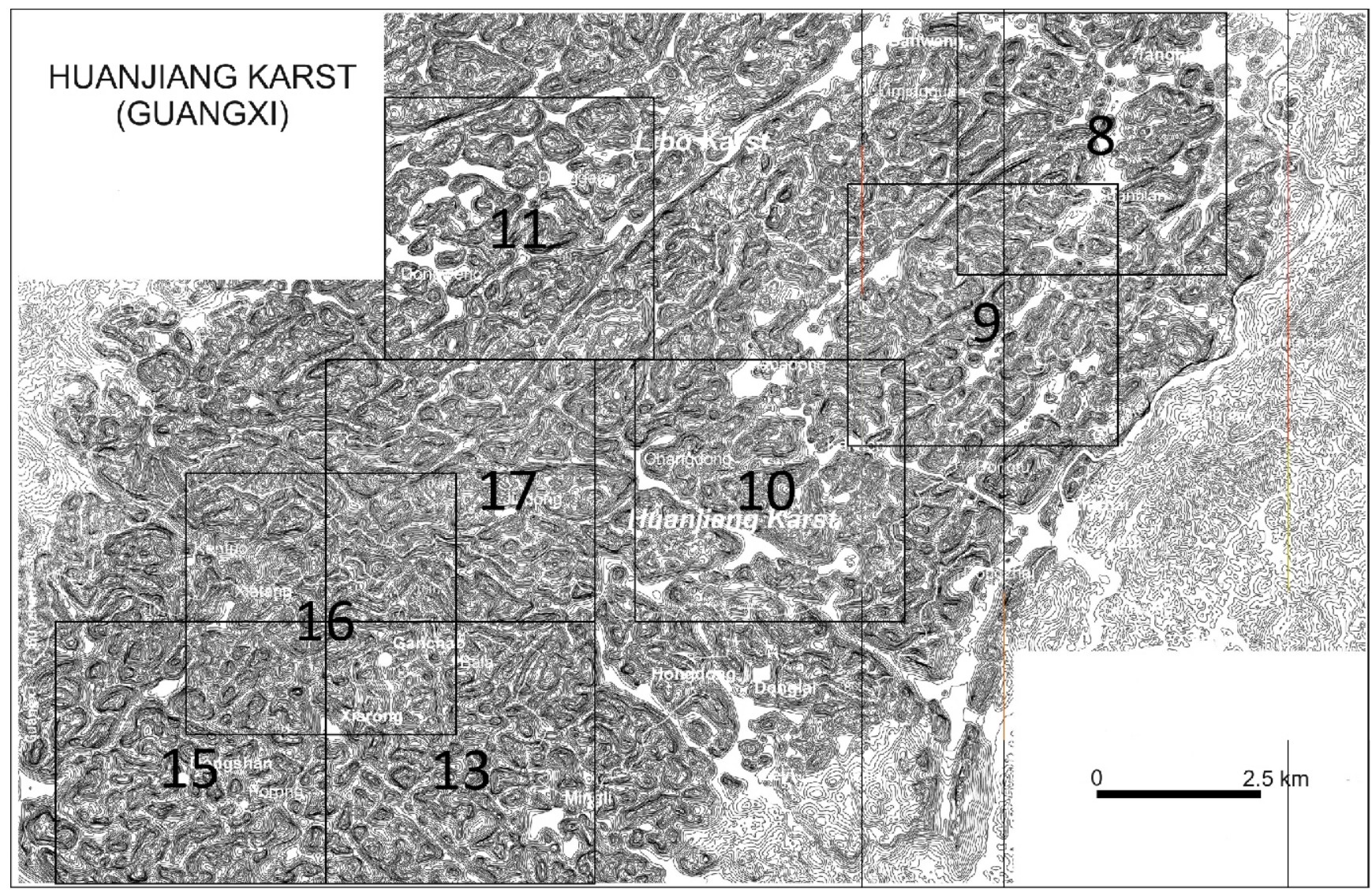

Fig. 4. The topographical draft of the Huanjiang region along with sub-regions (see Table 1) chosen for the fractal analysis (on the basis of South China Karst nomination, 2013, modified) 
other sub-regions possessing visible (also on the maps) morphological and morphometric characteristics of both types of karst (fenglin and fengcong in different proportions) were referred to as so-called mixed cases. Thus, a "full spectrum" of karst types was chosen, starting from classic fenglin through the mixed types and finally to classic fengcong karst. In summary, from both main regions, 17 sub-regions with diverse relief were selected (Figs. 3 and 4). All the chosen regions have the same dimension and scale. They are squares of $4.5 \mathrm{~km}$ side length and $20.25 \mathrm{~km}^{2}$ in area.

Next, for further analysis, the topographical maps (with contour lines) were transformed in accordance with their basic morphological elements - convex (hills and towers) and concave (depressions, valleys and plains) - into digital images, where white fields refer to the concave forms and black fields refer to the convex forms (Figs. 5 and 6). Based on these transformed images, the cover factors of the given areas, the ratios of black to white pixels, were calculated.

During the second step of work, fractal dimensions of the digital images were calculated. Calculations of capacity and correlation fractal dimensions rely on counting regularly distributed, non-overlapping boxes for the capacity dimension or randomly distributed circles (which can overlap) for the correlation dimension covering a given area. The final numbers of counts equal the sum of those boxes or circles in which at least one pixel of the object was detected. During the procedure, the sizes of boxes and circles are scaled. This, of course, modifies the total number of "non-zero" boxes; however, the log-log dependence between the number of counts covering a given karst area and the scalable box size or the circle diameter is linear within a wide range of sizes. The slope of this linear dependence is called the capacity (box) dimension or the correlation dimension depending on the figure (square or circle) used for counting. Obviously, the fractal dimension of a rectangle or other normal two-dimensional figures always equals 2 . To be more precise, the capacity fractal dimension can be calculated from the following formula (Baker and Gollub, 1996; Andreychouk et al., 2013):

$$
d_{\text {cap }}=\lim _{\varepsilon \rightarrow 0} \frac{\log (N(\varepsilon))}{\log L+\log (1 / \varepsilon)} \approx \frac{\log (N(\varepsilon))}{\log (1 / \varepsilon)}
$$

where: $N(\varepsilon)-$ the number of counted squares as a function of the counting square side length $\varepsilon$ and the size of object $L$.

In other words, $d_{c a p}$ can be calculated from the slope in the linear part of the relation between $\log (N /(\varepsilon))$ and $\log (1 / \varepsilon)$. For the correlation dimension, we have:

$$
d_{\text {cor }}=\lim _{R \rightarrow 0}\left(\frac{-\log (A)}{\log (R)}+\frac{\log (C(R))}{\log (R)}\right) \approx \frac{\log (C(R))}{\log (R)}
$$

where: $C(R)$ - the counter of circles covering image pixels, $R$ - the radius of a circle, and $A$ - the constant in the relation $C(R)=A \cdot R^{d_{\text {cor }}}$.

Hence, $d_{c o r}$ can be calculated from the slope in the linear part of the relation between $\log (C(R))$ and $\log (R)$. In many situations, both dimensions are comparable; however, the correlation dimension contains information about, as the name states, correlations between spatial distributions of matter at different scales (magnifications). The capacity fractal dimension, on the other hand, measures just the spatial presence or absence of matter as the scale is changed.

\section{RESULTS}

The results of the calculated fractal dimensions and cover factors can be found in Table 1. As mentioned before, the elaborated sub-regions were chosen in such a way to include both classic karst types of fenglin karst and fengcong karst and mixed cases (Figs. 3-6). "Pure" fenglin and fengcong types were designated as such and chosen on the maps, which are equivalent to the literature data describing their specific characteristics in the Chinese understanding of karst. The regions of interest are directly indicated on the maps. Calculated parameters, characterizing basic and mixed karst types, provide concrete numerical characteristics for separate specific types and enable spatial localization of the transitional types in relation to the basic types (Table 1).

For the capacity fractal dimension, its value increases gradually from 1.550 to 1.853 , along with the transition from fenglin to fengcong. Resulting from the analysis of the capacity fractal dimension values and in comparison with the associated cover factors, the highest level of fractality (the smallest values) belongs to fenglin karst and the smallest level (the highest values) to fengcong karst. Generally, there is an obvious correlation between calculated fractal dimensions and cover factors.

A similar conclusion can be derived from the analysis of the correlation fractal dimension and the associated values of the cover factor. The calculated values of this fractal dimension change from 1.435 to 1.823 , showing an unequivocal tendency of increase from fenglin to fengcong. Similar to the capacity dimension values, fenglin significantly differs from the other types, while when approaching fengcong, we observe partial overlap of the calculated dimension.

The analysis of the cover factor tendencies shows that its values obviously change almost by a factor of 3 from the minimum for the fenglin karst to the maximum value for the fengcong karst, namely, from 0.321 to 0.856 . However, the values do not overlap and refer to specific numerical ranges and thus provide a quantitative qualification of all types of karst. These tendencies are clearly visible in Figure 7 . However, the oscillatory behaviour of the dependencies at the beginning and near the end of the curve is striking. The general decrease in the fractal dimensions from approximately 0.6 to 0.4 indicates the gradual degradation of the relief structure starting from more condensed and regular shapes to more non-uniform and fractal-like structures. At the next step of evolution, however, for cover factors exceeding 0.4 , fractal dimensions increase again, which can be explained as the occurrence of the actual fractal structures. For the oscillatory behaviour noted, the effect is caused just when entering transitional (mixed) areas where new factors cause the appearance of bifurcations, which are seen as rapid, non-continuous changes in geometric parameters.

\section{DISCUSSION}

Due to these results, the following important questions arise: (1) do fractal quantitative characteristics (being a kind of parameterization) and their assignment to the types of karst studied have any "practical" (identification) importance for such types of karst morphology, apart from the mathematical context?; (2) how are fractal characteristics correlated with the cover factor, and may we use both types of parameterizations for geomorphological purposes?

To facilitate the analysis and find the answers to these questions, we can use an additional table (Table 2). The table summarizes the data included in Table 1 and classifies them 


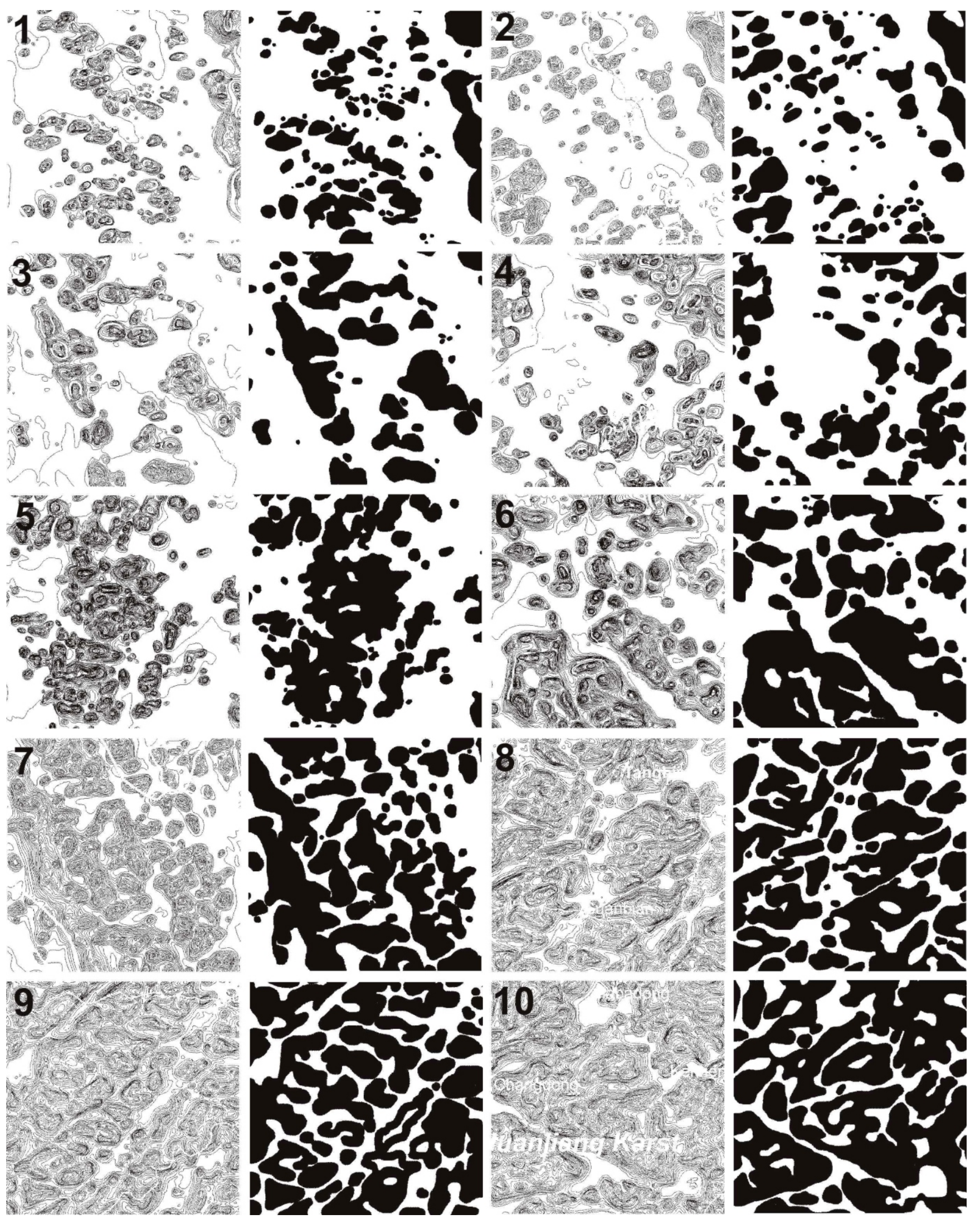

Fig. 5. The chosen regions under investigation (on the left - topographical picture, on the right - the associated transformed image on the basis of the convex and concave forms of the karst relief) 

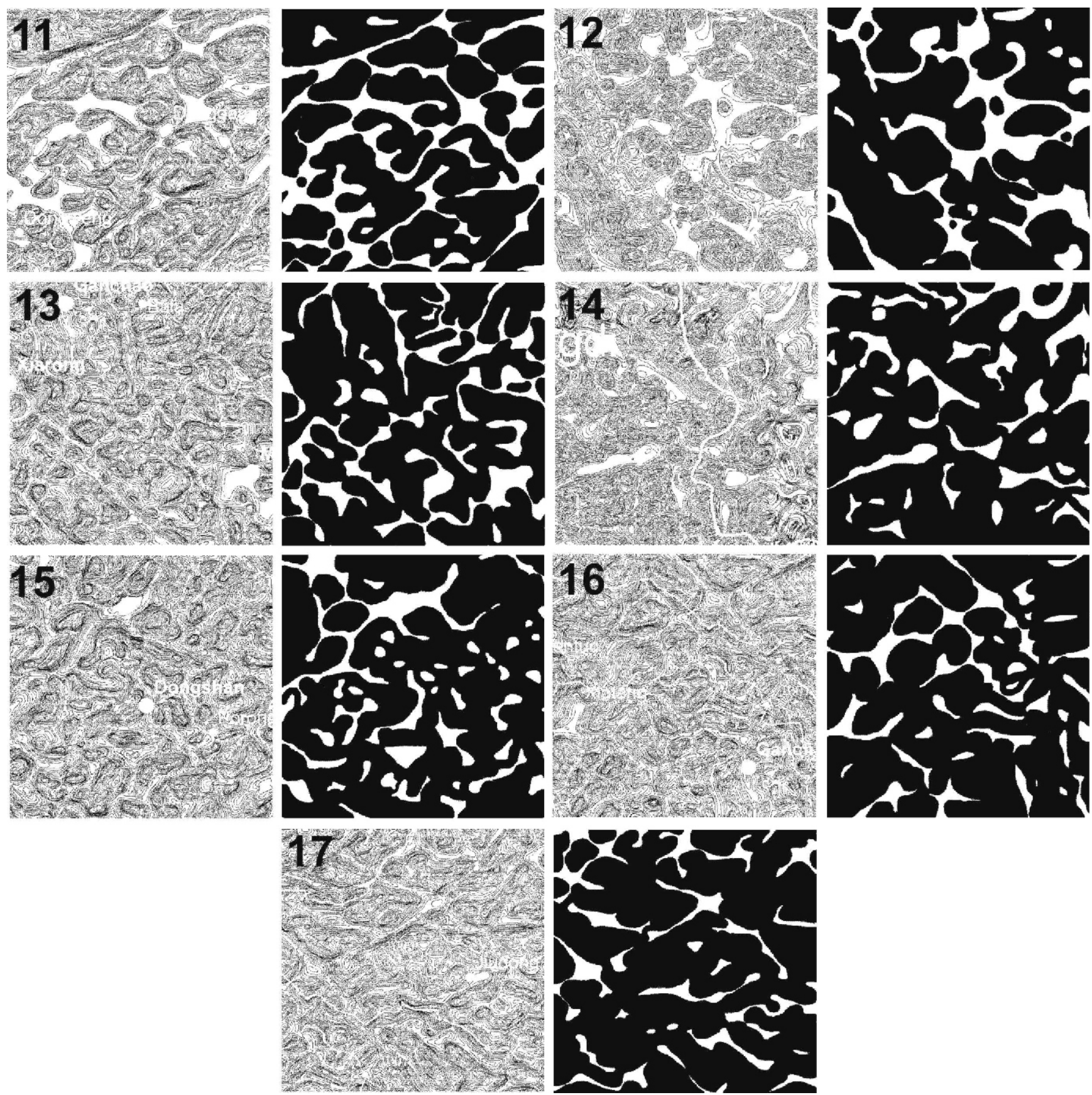

Fig. 6. The chosen regions under investigation (on the left - topographical picture, on the right - the associated transformed image on the basis of the convex and concave forms of the karst relief; continuation of Fig. 5)

Indexes of the regions (compare Table 1) are as follows: $11-\mathrm{FC}_{\mathrm{t} 4}, 12-\mathrm{FC}_{\mathrm{t} 5}, 13-\mathrm{FC}_{1}, 14-\mathrm{FC}_{2}, 15-\mathrm{FC}_{3}, 16-\mathrm{FC}_{4}, 17-\mathrm{FC}_{5}$

into groups with relatively similar values of fractal and cover factor parameters. Those groups represent ranges of values that can refer to specific types of karst landscapes: fenglin, fengcong and their mixed forms. As noted in the previous paragraph, the adequacy of the first four and the last five studied sub-regions being classified as fenglin and fengcong karst, respectively, results not from our calculations but from a priori knowledge that the chosen areas truly belong to the types described and represent them. Hence, having typological markers characterizing the extreme positions provides constraints for analysing the inner numerical data between the extreme values of the fenglin and fengcong types.
To answer the first question, both fengcong and fenglin types of tropical karst landscapes, as well as their mixed types, possess fractal properties, and their values clearly show a direct trend of changes towards an increase in fractality from fengcong to fenglin. From the analysis of the data presented in Table 1, it can be concluded that each type of karst is characterized in general by its own range of calculated values. For the case of fenglin, these ranges of values are pure in a sense that, for a given type of karst, the fractal dimension values are not superimposed. In the case of correlation dimension analysis for the other types of karst (not fenglin), this method is less useful due to some level of overlap of the calculated values, regard- 


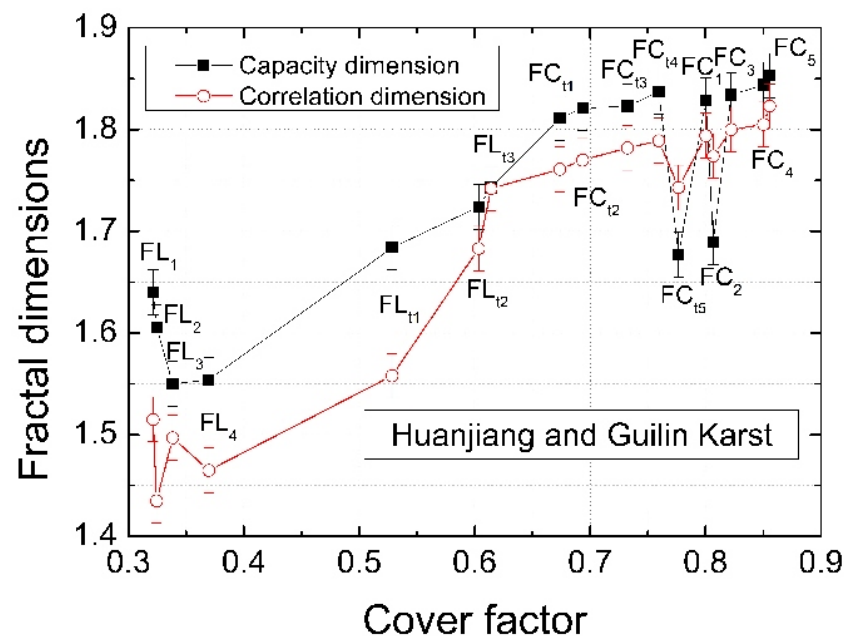

Fig. 7. Dependence of capacity and fractal correlation dimensions on the cover factor for the studied areas in South China Karst (obtained uncertainties are equal to the slope uncertainty in the linear regressions used to calculate fractal dimensions on the basis of the equations provided in the text)

less of this tendency (Table 2). Therefore, we believe that the fractal characteristics of the types of sculpture tested have a limited range of use and can scarcely serve as unambiguous typological markers. They can nevertheless be complementary to other characteristics. Their recommended identification values are proposed in Table 2.

Concerning the second question, we can confirm the presence of a high correlation between fractal characteristics and cover factor yatues, but there are also some fluctuations in their mutual behaviour (Fig. 7). Additionally, we can see (Tables 1 and 2) that in the case of cover factor, there is no superposition of numerical values characterizing the basic and mixed types of karst, and the data for individual types fit in the appropriate numerical ranges (Table 2). More importantly, in the case of the transition from pure fenglin to mixed (with fengcong) types, the continuity has been clearly disturbed (interrupted), which may be very useful for identification and typology, i.e., distinguishing fenglin and mixed types (Tables 1 and 2). However, it is highly possible that the observed leap (from 400 to 500 in Table 2) may result not from reasons occurring in nature but from methodological circumstances, i.e., from the fact that potential types that could fill the numerical gap have not been chosen on the maps and have been not analysed.

Thus, using a simple method of counting the ratio of convex to concave areas and calculating the cover factors, we can conclude a given type of tropical karst, referring to the Chinese varieties first. Numerical ranges characterizing pure and mixed types of karst on the basis of both the cover factor and the fractal characteristics are shown in Table 2. The continuity (except for the transition point from fenglin to fenglin-fengcong, which can be caused by unknown reasons) of the cover factor, and even the overlap of numerical areas in the case of fractal parameters, is the most normal thing that reflects the real lack of sharp transitions from one type of karst to another. This can also point to their genetic (evolutionary) unity.

\section{CONCLUSIONS}

The fenglin and fengcong types of tropical karst relief (landscapes), as well as their mixed types, possess fractal properties that can be expressed as fractal dimensions, for example, capacity and/or correlation fractal dimensions. In general, they can be used for parameterization of relief. However, mutual overlap between numerical ranges significantly limits the possibilities of using fractal characteristics for the purpose of classification and identification of karst sculpture types. Nevertheless, the stable upward trend of their changes may serve as a good indicator or even as a measure of the gradual evolutionary degradation (disintegration, disorganization) of areas in the direction from more ordered fengcong towards the less ordered fenglin.

Ranges of values of fractal dimensions and cover factors that can be used to identify the tropical karst relief types based on the Chinese (fenglin, fengcong and their mixtures) types (subtypes)

\begin{tabular}{|c|c|c|c|c|}
\hline $\begin{array}{c}\text { Groups of studied areas } \\
\text { (see Table 1) }\end{array}$ & $\begin{array}{l}\text { Capacity fractal } \\
\text { dimension }\end{array}$ & $\begin{array}{l}\text { Correlation fractal } \\
\text { dimension }\end{array}$ & $\begin{array}{l}\text { Cover factor (black } \\
\text { pixels/all pixels) }\end{array}$ & Karst types \\
\hline $1-\mathrm{FL}_{1}$ to $4-\mathrm{FL}_{4}$ & $1.550-1.640$ & $1.435-1.515$ & $0.321-0.370$ & \multirow{4}{*}{ fenglin } \\
\hline Average value & 1.587 & 1.478 & 0.338 & \\
\hline Value amplitude & 0.09 & 0.08 & 0.049 & \\
\hline Assigned range of values & $1.50-1.65$ & $1.40-1.50$ & $0.300-0.400$ & \\
\hline $5-\mathrm{FL}_{\mathrm{t} 1}$ to $7-\mathrm{FL}_{\mathrm{t} 3}$ & $1.684-1.743$ & $1.558-1.742$ & $0.528-0.614$ & \multirow{4}{*}{$\begin{array}{l}\text { fenglin-fengcong } \\
\text { (mixed fenglin) }\end{array}$} \\
\hline Average value & 1.718 & 1.661 & 0.582 & \\
\hline Value amplitude & 0.059 & 0.184 & 0.086 & \\
\hline Assigned range of values & $1.68-1.75$ & $1.55-1.75$ & $0.500-0.650$ & \\
\hline $8-F_{t 1}$ to $12-F_{t 5}$ & $1.677-1.837$ & $1.743-1.789$ & $0.674-0.777$ & \multirow{4}{*}{$\begin{array}{l}\text { fengcong-fenglin } \\
\text { (mixed fengcong) }\end{array}$} \\
\hline Average value & 1.793 & 1.769 & 0.727 & \\
\hline Value amplitude & 0.16 & 0.046 & 0.103 & \\
\hline Assigned range of values & $1.68-1.84$ & $1.74-1.79$ & $0.650-0.800$ & \\
\hline $13-\mathrm{FC}_{1}$ to $17-\mathrm{FC}_{5}$ & $1.689-1.853$ & $1.774-1.823$ & $0.800-0.856$ & \multirow{4}{*}{ fengcong } \\
\hline Average value & 1.810 & 1.799 & 0.827 & \\
\hline Value amplitude & 0.164 & 0.049 & 0.056 & \\
\hline Assigned range of values & $1.69-1.86$ & $1.77-1.83$ & $0.800-0.900$ & \\
\hline
\end{tabular}


A more effective recognition tool for determining both basic and mixed tropical karst types is the cover factor. This parameter shows numerical variabilities and tendencies which makes it suitable for typological parameterization and identification of the tropical karst types in this study. The presence of a clear correlation between cover factor and fractal values allows using the latter as a complementary tool in typological identification of tropical karst types.

The proposed method and data obtained cannot be used automatically for other areas (outside of South China Karst country) with cone and tower karsts. Fengcong and fenglin as "Chinese" types of tropical karst relief are specific in morphol- ogy and morphometry and differ morphogenetically from other regions of tropical karst (not fundamentally, but in details resulting from specific regional conditions). There is a high probability that they represent in many cases the evolutionary stages of karst relief development in this area, making the classification of their transitional types (stages) necessary. Therefore, our results and quantitative characteristics reflect the peculiarities of the fencing and fenglin types of tropical karst relief primarily.

Acknowledgements. The authors would like to thank very much the reviewers of this manuscript. Their comments and suggestions in significant degree raised the quality of the paper.

\section{REFERENCES}

Andreychouk, V., Dłużewski, M., 2015. Kras Południowochiński (in Polish). Geographic Workshop Materials, China 2015: 73-89.

Andreychouk, V., Blachowicz, T., Domino, K., 2013. Fractal dimensions of cave for exemplary gypsum cave-mazes of Western Ukraine. Landform Analysis, 22: 3-8.

Baker, G.L., Gollub, J.P., 1996. Chaotic Dynamics, An Introduction. Cambridge University Press, New York.

Balazs, D., 1973. Relief types of tropical karst areas. In: Proceedings of the Symposium on Karst Morphogenesis, International Geographical Union, European Region Conference - Hungary: 16-32. Budapest.

Blachowicz, T., Andreychouk, V., 2016. Quantitative estimation of 3D cave networks complexity using random walk analysis. Landform Analysis, 29: 91-96.

Brook, G.A., Ford, D.C., 1978. The origin of labyrinth and tower karst and the climatic conditions necessary for their development. Nature, 275: 493-496.

Chen, X., ed., 1988. South China Karst 1. Scientific Research Center of Slovenian Academy of Sciences and Arts, Ljubljana.

Chilès, J.P., 1988. Fractal and geostatistical methods for modelling of a fracture network. Mathematical Geology, 20: 631-654.

Curl, R.L., 1986. Fractal dimensions and geometries of caves. Mathematical Geology, 18: 765-783.

Danes, J., 1911. Le karst du type "Goenoeng Sewu" ou "cockpit country". Bulletin de la Société Serbe de Geographie, 11 310-313.

Feder, J., 1988. Fractals. Plenum, New York.

Ford, D., Williams, P., 1989. Karst Geomorphology and Hydrology. Unwin Hyman, London.

Ford, D., Williams, P., 2007. Karst Geomorphology and Hydrology John Wiley \& Sons, Ltd., London.

Gunn, J., ed., 2004. Encyclopedia of Caves and Karst Science. Fitzroy Dearborn, New York.

Gvozdetskiy, N.A., 1988. Karst Landscapes. Moscow University, Moscow.

Halvin, S., Ben-Avraham, D., 2002. Diffusion in disordered media. Advances in Physics, 51: 187-292.

Jennings, J.N., 1985. Karst Geomorphology. Basil Blackwell, Oxford.

Kambesis, P.N., Larson, E.B., Mylroie, J.E., 2015. Morphometric analysis of cave patterns using fractal indices. Geological Society of America, Special Paper, 516: 1-20.

Laverty, M., 1987. Fractals in karst. Earth Surface Processes and Landforms, 12: 475-480.

Lehmann, H., 1936. Morphologische Studien auf Java. Geographische Abhandlungen, Serie 3, 9: 1-114.

Lehmann, O., 1926. Die Geographischen Ergebnisse der Reise durch Kweitschou. Expedition Dr Handel-Mazetti 1914-1918. Denkschriften der Kaiserlichen Akademie der Wissenschaften Mathematisch-Naturwissenschaftliche Classe, 100: 77-99.
Li Yu, H., 2002. Morphological types and their features of Shilin Karst in Yunnan, China. Carsologica Sinica, 21: 165-172.

Liu, J.R., 1997. The development history of the Guangxi tropical karst geomorphology and its sequences. Carsologica Sinica, 16: $346-350$.

Liu, J.R., Huang, G.B., Huang, X.L., 2001. Discussion on The evolution of different types of regional tropical karst landform in Guangxi. Carsologica Sinica, 20: 247-252.

Maramathas, A.J., Boudouvis, A., 2006. Manifestation and measurement of the fractal characteristics of karst hydrogeological formations. Advances in Water Resources, 29: 112-116.

Monroe, W.H., 1996. Formation of tropical karst topography by limestone solution and precipitation. Caribbean Journal of Science, 6: 1-7.

Pardo-Igúzquiza, E., Durán, J.J, Robledo, R., Guardiola, C., Luque, J.A., Martos, S., 2014. Fractal modelling of karst conduits. Lecture Notes in Earth System Science, Mathematics of Planet Earth. In: Proceedings of the 15th Annual Conference of the International Association for Mathematical Geosciences, Springer Berlin Heidelberg: 217-220.

Pfeffer, K.H., 1993. Zur Genese tropischer Karstgebiete auf den Westindischen Inseln. Zeitschrift für Geomorphologie, N.F. Supplement-Band, 93: 137-58.

Pham, K., 1985. The development of karst landscape in Vietnam. Acta Geologica Polonica, 35: 305-324.

Salomon, J.N., 2000. Précis de Karstologie. Presses Universitaires de Bordeaux.

Salomon, J.N., Pulina, M., 2005. Les karsts des régions climatiques extrêmes. Presses Universitaires de Bordeaux.

Silar, J., 1996. Development of tower karst in China and North Vietnam. National Speleological Society Bulletin, 27: 35-46.

Song, L., Deng, Z., Mangin, A., 1993. Structure, Functioning and Evolution of Karst Aquifers and Landforms in Conical Karst, Guizhou, China. Sino-French Karst Hydrogeology Collaboration. Moulis.

South China Karst nomination, 2013. Phase II, nomination document for World's Heritage List of UNESCO. Ministry of Housing and Urban-Rural Development People's Republic of China.

Sweeting, M.M., 1958. The Karstlands of Jamaica. The Geographical Journal, 6: 184-199.

Sweeting, M.M., 1972. Karst Landforms. Macmillan, London.

Sweeting, M.M., 1986. Limestone landscape of South China. Geology Today, 2: 11-16.

Sweeting, M.M., 1989. Cone and tower karst of South China. Geography Review, 3: 2-6

Sweeting, M.M., 1995. Karst in China, its Geomorphology and Environment. Springer-Verlag, Berlin.

Waltham, T., 2008. Fengcong, fenglin, cone karst and tower karst. Cave and Karst Science, 35: 77-88. 
Waltham, T., 2011. Fengcong, fenglin, cone karst and tower karst. Speleogenesis and Evolution of Karst Aquifers, 11: 1-14.

Wang, X., 1986. U-series age and oxygen carbon isotopic features of speleothems in Guilin. In: Proceedings of the $9^{\text {th }}$ International Congress of Speleology, Spain (1): 284-286.

Williams, P., 1978. Karst research in China. British Cave Research Association, 5: 29-46.

Williams, P., 1987. Geomorphic inheritance and the development of tower karst. Earth Surface Processes and Landforms, 12: 453-465.

Williams, P., 1988. Hydrogeological control and the development of cocpit and tower karst. In: Proceedings of the 21 Congress of the International Association of Hydrogeologists, Guilin, China, Vol. XXI , Part I: 281-290.

Wissmann, H., von., 1954. Der Karst der humiden heißen und sommerheißen Gebiete Ost-Asiens. Erdkunde, 8: 122-130.

Xiong, K.N., 1992. Morphometry and evolution of fenglin karst in the Shuicheng area, western Guizhou, China. Zeitschrift für Geomorphologie N.F., 36: 227-248.

Xiong, K.N., 1994. Hydrodynamic genetics of cone karst and Tower Karst. Carsologica Sinica, 13 (3): 237-246.

Yang, M.D., 1993. Geomorphologic Structure and Evolution of Tropical Karst. Earthquake Press, Beijing

Yu, Z.D., 2003. The origin and evolution of the karst landscape, Yunnan. Geology, 22: 1-15.
Yuan, D., 2004. Yangshuo karst, China. In: Encyclopedia of Caves and Karst Science (ed. J. Gunn.): 781-783. Fitzroy Dearborn, New York.

Yuan, D., 1991. Karst of China. Geological Publishing House, Beijing.

Zhang, Z., 1980. Karst types in China. Geological Journal, 4: $541-570$.

Zhu, D.H., 1982. Evolution of Peak Cluster-Depression in Guilin area and morphometric measurement. Carsologica Sinica, 10: 127-134.

Zhu, D.H., 1992. China karst tourism resources and their position in the world. Carsologica Sinica, 11: 340-345.

Zhu, X.W., 1988. Guilin Karst. Shanghai Scientific and Technical Publishers.

Zhu, X.W., 1991a. New considerations on characteristics and evolution of fenglin karst, 1. Carsologica Sinica, 10: 51-62.

Zhu, X.W., 1991b. New considerations on characteristics and evolution of fenglin karst, 2. Carsologica Sinica, 10: 137-156.

Zhu, X.W., 1991c. New considerations on characteristics and evolution of fenglin karst, 3. Carsologica Sinica, 10: 171-182.

Zhu, X.W., 2005. Karst areas and types in China. Geographische Rundschau, 1: 37-47.

Zhu, X.W., Wang, X.Y., Zhu, D.H., Qin, H., 1988. Research of Guilin Karst Geomorphology and Cave. Geological Publishing House, Beijing. 